\title{
Cardiac auscultation poorly predicts the presence of valvular heart disease in asymptomatic primary care patients
}

\author{
Syed K M Gardezi, ${ }^{1,2}$ Saul G Myerson, ${ }^{1,2}$ John Chambers, ${ }^{3}$ Sean Coffey, ${ }^{4}$ \\ Joanna d'Arcy, ${ }^{1}$ F D Richard Hobbs, ${ }^{5}$ Jonathan Holt, ${ }^{6}$ Andrew Kennedy, ${ }^{1}$ \\ Margaret Loudon, ${ }^{1}$ Anne Prendergast, ${ }^{7}$ Anthony Prothero, ${ }^{1}$ Joanna Wilson, ${ }^{1}$ \\ Bernard D Prendergast ${ }^{3}$
}

'Department of Cardiology, Oxford University Hospitals NHS Foundation Trust, Oxford, UK ${ }^{2}$ Division of Cardiovascular Medicine, Radcliffe Department of Medicine, University of Oxford, Oxford, UK

${ }^{3}$ Department of Cardiology, St Thomas' Hospital, London, UK

${ }^{4}$ Department of Medicine, Dunedin School of Medicine, University of Otago, Dunedin, New Zealand

${ }^{5}$ Nuffield Department of Primary Care Health Sciences, Radcliffe Primary Care Building, University of Oxford, Oxford, UK

${ }^{6}$ Bicester Health Centre, Bicester, UK

${ }^{7}$ Donnington Health Centre, Oxford, UK

\section{Correspondence to}

Dr Bernard D Prendergast, Department of Cardiology, St Thomas' Hospital, London SE1 7EH, UK; bernard.prendergast@ gstt.nhs.uk

Received 26 January 2018 Revised 30 April 2018 Accepted 2 May 2018 Published Online First 24 May 2018

\section{Linked}

- http://dx.doi.org/10.1136/ heartjnl-2018-313474

\section{Check for updates}

To cite: Gardezi SKM,

Myerson SG,

Chambers J, et al. Heart

2018:104:1832-1835.

\section{ABSTRACT}

Objective Cardiac auscultation is a key clinical skill, particularly for the diagnosis of valvular heart disease (VHD). However, its utility has declined due to the widespread availability of echocardiography and diminishing emphasis on the importance of clinical examination. We aim to determine the contemporary accuracy of auscultation for diagnosing VHD in primary care.

Methods Cardiac auscultation was undertaken by one of two experienced general practitioners (primary care/family doctors) in a subset of 251 asymptomatic participants aged $>65$ years undergoing echocardiography within a large community-based screening study of subjects with no known VHD. Investigators were blinded to the echocardiographic findings. Newly detected VHD was classified as mild (mild regurgitation of any valve or aortic sclerosis) or significant (at least moderate regurgitation or mild stenosis of any valve).

Results Newly identified VHD was common, with mild disease in 170/251 participants (68\%) and significant disease in 36/251 (14\%). The sensitivity of auscultation was low for the diagnosis of mild VHD (32\%) but slightly higher for significant VHD (44\%), with specificities of $67 \%$ and $69 \%$, respectively. Likelihood ratios were not statistically significant for the diagnosis of either mild or significant VHD in the overall cohort, but showed possible value for auscultation in non-overweight subjects (body mass index $<25 \mathrm{~kg} / \mathrm{m}^{2}$ ).

Conclusion Cardiac auscultation has limited accuracy for the detection of VHD in asymptomatic patients and is a poor diagnostic screening tool in primary care, particularly for overweight subjects. Ensuring easy access to echocardiography in patients with symptoms suggesting VHD is likely to represent a better diagnostic strategy.

\section{INTRODUCTION}

Cardiac auscultation is one of the key clinical skills used by physicians in the diagnosis and assessment of valvular heart disease (VHD). However, its perceived utility has declined as a consequence of diminishing emphasis on the importance of clinical examination and the widespread availability of echocardiography. ${ }^{1}$ While previous studies have evaluated the use of auscultation in the diagnosis of VHD (mainly in children) among hospital doctors, ${ }^{2-6}$ none have assessed the auscultation skills of general practitioners (primary care/family doctors) in older subjects (in whom VHD is more common). Primary care practitioners rarely have immediate access to echocardiography, and practical clinical skills such as auscultation are used for diagnostic assessment.

Symptoms present late in the natural history of VHD, resulting in delayed referral for specialist assessment and consideration of surgical or percutaneous intervention. The Oxfordshire Valvular Heart Disease Population Cohort Study (OxVALVE) is the first prospective community-based study of VHD worldwide $^{7}$ and has demonstrated a high prevalence of undiagnosed VHD in older people. In this substudy, we evaluated the accuracy of cardiac auscultation by primary care/family doctors in the diagnosis of VHD, with transthoracic echocardiography as the reference standard.

\section{METHODS}

We identified 251 individuals undergoing echocardiography at two primary care sites participating in OxVALVE-a large 4000-patient community-based prospective screening study identifying the prevalence of undiagnosed VHD in asymptomatic subjects aged over 65 years.

Systematic cardiac auscultation, incorporating assessment of pulse character and murmur radiation (where appropriate), was undertaken by one of two fully trained primary care/family doctors. In the UK, these practitioners complete a prescribed 3 -year training programme including a variety of clinical placements. In subsequent independent practice, they see unselected patients in primary care, covering presentations across all areas, including gerontology, gynaecology, adult internal medicine and paediatrics. Each of the participating primary care/family doctors had greater than 10 years of clinical experience (although neither of them had received specialist cardiology training). They used an acoustic stethoscope under 'real world conditions' without the knowledge of the echocardiographic findings. During the same study visit, heart sounds were recorded using an electronic 
stethoscope (3M Littmann Electronic Stethoscope Model 3200), and these sounds were analysed at a later date by two consultant cardiologists (without visual analysis of the waveform or knowledge of the echocardiographic findings).

An investigating physician or sonographer undertook detailed transthoracic echocardiography with a Vivid-Q portable machine (Vingmed-General Electric, Horton, Norway) immediately following auscultation using standard views according to the British Society of Echocardiography guidelines. Valve anatomy, physiology and the severity of VHD were classified according to international guideline criteria. ${ }^{8-10}$ For the purposes of this analysis, VHD was defined as either mild (aortic sclerosis or mild regurgitation of any valve) or significant (at least moderate regurgitation or mild stenosis of any valve).

Standard measures of diagnostic accuracy (sensitivity, specificity, positive and negative predictive values, positive and negative likelihood ratios) were determined using echocardiographic assessment as the reference standard. We performed separate analyses to determine if diagnostic accuracy of auscultation by primary care/family doctors was different in those with or without high body mass index (BMI $\geq 25 \mathrm{~kg} / \mathrm{m}^{2}$ ). For the cardiologists, $2 \times 2$ confusion matrices based on their ratings were combined using means for the purposes of analysis. Statistical analyses were performed using Stata V.14.2 (StataCorp) and R V.3.4.3 (R Foundation for Statistical Computing).

\section{RESULTS}

The mean age of study participants was $75 \pm 6$ years $(51 \%$ male). Cardiac murmurs were heard in 82 subjects ( 80 systolic, 2 diastolic) by the primary care/family doctors with a higher likelihood of detection in women. By comparison, cardiac murmurs were heard in 102 subjects (79 systolic, 23 diastolic) by cardiologists.

Echocardiography demonstrated mild and significant VHD in 170/251 (68\%) and 36/251 (14\%) participants, respectively. Details concerning the accuracy of VHD diagnosis by auscultation are provided in table 1. Detection of mild VHD by general practitioners was modest overall (sensitivity 32\%, specificity $67 \%$ ) but slightly better for significant VHD (sensitivity 44\%, specificity 69\%). Conversely, the negative predictive value of cardiac auscultation for the exclusion of significant VHD was reasonable (88\%). However, this was similar to the proportion of subjects without significant VHD in the cohort (86\%), indicating that auscultation did not aid the separation of those with/ without VHD. This was supported by the positive and negative likelihood ratios which suggested that auscultation had poor diagnostic yield, with no statistically significant likelihood ratios for the prediction of either mild or significant VHD (table 1). Subanalysis according to BMI (table 2) suggested that this yield was particularly low in overweight patients (BMI $\geq 25 \mathrm{~kg} / \mathrm{m}^{2}$ ),

Table 1 Accuracy of cardiac auscultation by general practitioners and cardiologists in the diagnosis of VHD, compared with echocardiography as the reference standard ( $95 \%$ Cls in parentheses)

\begin{tabular}{|c|c|c|c|c|}
\hline Significant VHD & & & & \\
\hline (A) General practitic & & & & \\
\hline & Positive & Negative & Total & \\
\hline Murmur present & 16 & 66 & 82 & PPV: $20 \%(12 \%$ to $30 \%)$ \\
\hline Murmur absent & 20 & 149 & 169 & NPV: $88 \%(82 \%$ to $93 \%)$ \\
\hline Total & 36 & 215 & 251 & Prev: $14 \%(10 \%$ to $19 \%)$ \\
\hline & Sens: $44 \%(28 \%$ to $62 \%)$ & Spec: $69 \%(63 \%$ to $75 \%)$ & & \\
\hline & LR+: 1.45 (0.95 to 2.20$)$ & LR-: 0.80 (0.59 to 1.09$)$ & & \\
\hline (B) Cardiologists ( $m$ & & & & \\
\hline & Positive & Negative & Total & \\
\hline Murmur present & 11 & 40 & 51 & PPV: $22 \%(11 \%$ to $35 \%)$ \\
\hline Murmur absent & 25 & 175 & 200 & NPV: $88 \%$ ( $82 \%$ to $92 \%)$ \\
\hline Total & 36 & 215 & 251 & Prev: $14 \%(10 \%$ to $19 \%)$ \\
\hline & Sens: $31 \%(16 \%$ to $48 \%)$ & Spec: $81 \%$ ( $76 \%$ to $86 \%)$ & & \\
\hline & LR+: 1.64 (0.93 to 2.89$)$ & LR-: 0.85 (0.68 to 1.07$)$ & & \\
\hline Mild VHD & & & & \\
\hline (C) General practitic & & & & \\
\hline & Positive & Negative & Total & \\
\hline Murmur present & 55 & 27 & 82 & PPV: $67 \%$ (56\% to $77 \%)$ \\
\hline Murmur absent & 115 & 54 & 169 & NPV: $32 \%(25 \%$ to $40 \%)$ \\
\hline Total & 170 & 81 & 251 & Prev: $68 \%(62 \%$ to $73 \%)$ \\
\hline & Sens: $32 \%(25 \%$ to $40 \%)$ & Spec: $67 \%$ (55\% to $77 \%)$ & & \\
\hline & LR+: 0.97 (0.67 to 1.41$)$ & LR-: 1.01 (0.84 to 1.22$)$ & & \\
\hline (D) Cardiologists (m & & & & \\
\hline & Positive & Negative & Total & \\
\hline Murmur present & 37 & 14 & 51 & PPV: $73 \%$ ( $58 \%$ to $84 \%)$ \\
\hline Murmur absent & 133 & 67 & 200 & NPV: $34 \%(27 \%$ to $40 \%)$ \\
\hline Total & 170 & 81 & 251 & Prev: $68 \%(62 \%$ to $73 \%)$ \\
\hline & Sens: $22 \%$ ( $16 \%$ to $29 \%)$ & Spec: $83 \%$ ( $73 \%$ to $90 \%)$ & & \\
\hline & LR+: 1.26 (0.72 to 2.19$)$ & LR-: 0.95 (0.83 to 1.07$)$ & & \\
\hline
\end{tabular}

LR+, positive likelihood ratio; LR-, negative likelihood ratio; NPV, negative predictive value; PPV, positive predictive value; Prev, prevalence; Sens, sensitivity; Spec, specificity; VHD, valvular heart disease. 
Table 2 Comparison of diagnostic accuracy of auscultation by general practitioners for the prediction of significant valvular heart disease (VHD), according to body mass index (BMI) above and below the upper limit of 'healthy weight' as defined by the World Health Organization $\left(25 \mathrm{~kg} / \mathrm{m}^{2}\right)$

\begin{tabular}{|c|c|c|c|}
\hline & $\mathrm{BMI}<25 \mathrm{~kg} / \mathrm{m}^{2}$ & $\mathrm{BMI} \geq 25 \mathrm{~kg} / \mathrm{m}^{2}$ & $\begin{array}{l}\text { P values for } \\
\text { difference } \\
\text { between groups }\end{array}$ \\
\hline$n$ & 86 & 165 & \\
\hline Significant VHD & $21(24 \%)$ & $15(9 \%)$ & 0.002 \\
\hline Sensitivity & $57 \%(34 \%-78 \%)$ & $27 \%(8 \%-55 \%)$ & 0.40 \\
\hline Specificity & $71 \%(58 \%-81 \%)$ & $69 \%(61 \%-76 \%)$ & 0.99 \\
\hline $\begin{array}{l}\text { Positive predictive } \\
\text { value }\end{array}$ & $39 \%(22 \%-58 \%)$ & $8 \%(2 \%-19 \%)$ & 0.01 \\
\hline $\begin{array}{l}\text { Negative predictive } \\
\text { value }\end{array}$ & $84 \%(71 \%-92 \%)$ & $90 \%(83 \%-95 \%)$ & 0.84 \\
\hline $\begin{array}{l}\text { Positive likelihood } \\
\text { ratio }\end{array}$ & $1.95(1.15-3.32)$ & $0.85(0.36-2.04)$ & 0.11 \\
\hline $\begin{array}{l}\text { Negative likelihood } \\
\text { ratio }\end{array}$ & $0.61(0.36-1.02)$ & $1.07(0.77-1.48)$ & 0.07 \\
\hline
\end{tabular}

$\mathrm{P}$ values are for the differences between groups ( $\mathrm{BMI}<25 \mathrm{vs} \geq 25$ ) and are based on

$\chi^{2}$ test, with the exception of Cochran's Q test for likelihood ratios.

although lower numbers in the subgroups precluded many statistically significant differences between these groups, and caution is required in interpreting subgroup analyses.

The assessment of recorded heart sounds by cardiologists was less sensitive but more specific for the detection of both mild (sensitivity 22\%, specificity $83 \%$ ) and significant (sensitivity $31 \%$, specificity $81 \%$ ) VHD. Similar to the primary care/family doctors, the negative predictive value of auscultation was high (88\%). However, the cardiologists' analysis of recorded heart sounds showed no statistically significant likelihood ratios for the overall prediction of VHD (table 1).

\section{DISCUSSION}

\section{Summary of findings}

In this study, among 251 asymptomatic elderly subjects, the prevalence of newly diagnosed mild and significant VHD detected using echocardiography was $68 \%$ and 14\%, respectively. Cardiac auscultation (blinded to the echocardiographic findings) demonstrated only modest sensitivity for the detection of VHD. Furthermore, both negative and positive likelihood ratios were close to unity, suggesting that auscultation did not provide useful discriminative information for the diagnosis of VHD in an asymptomatic elderly population. However, diagnostic accuracy is likely to be improved in those presenting with symptoms suggestive of VHD (which has not been examined in this study). Sub-group analysis has also suggested that clinical screening without the need for echocardiography may have greater utility in non-overweight subjects, but it may not hold in overweight subjects (BMI $>25 \mathrm{~kg} / \mathrm{m}^{2}$ ) where our data suggest that auscultation is less accurate.

\section{Comparison with existing literature}

Other studies indicate that the widespread availability of echocardiography has led to a decline in cardiac auscultation skills (and, by inference the ability to diagnose VHD) among medical students and postgraduate trainees across a wide range of medical specialties, including cardiology, paediatrics, internal medicine and family practice. ${ }^{11-13}$ Indeed, auscultation is frequently omitted from routine examination by primary care practitioners, even in the presence of cardiac symptoms. ${ }^{14}$ Proficiency in cardiac auscultation is low in the USA, Canada and England $^{15}$ and in one report, almost $20 \%$ of patients with severe aortic stenosis have been missed during cardiovascular examination by a cardiologist. ${ }^{16}$ Consistent with our findings, cardiac auscultation in one hospital-based study demonstrated sensitivities of $0 \%-37 \%$ and specificities of $85 \%-100 \%$ in the assessment of 294 patients with mainly regurgitant murmurs, using echocardiography as the reference standard. ${ }^{3}$

Earlier diagnosis of VHD is an important clinical goal to facilitate assessment in a specialist valve clinic, education concerning key symptoms and the prevention of infective endocarditis, and timely referral for surgery or percutaneous intervention. ${ }^{17}$ There are limited previous data concerning the accuracy of physical examination in subjects with asymptomatic $\mathrm{VHD}^{2}$ and echocardiographic population screening has a low yield for the detection of VHD in younger subjects, ${ }^{18} 19$ except in areas where childhood rheumatic heart disease remains highly prevalent. ${ }^{5}{ }^{6}$ Even in a large study of over 2000 patients undergoing open access echocardiography, only 127 (18\%) of 706 with a murmur had significant VHD. ${ }^{20}$

\section{Strengths and limitations}

The purpose of this study was to provide a real-world analysis of auscultation performed in an outpatient setting by primary care/ family doctors without specialist training in cardiology using echocardiography as the reference standard. Direct comparison of the accuracy of conventional cardiac auscultation by general practitioners and cardiologists in the same patients was not possible for logistical reasons. A resulting significant limitation of our indirect comparison was that the primary care/family doctors undertook conventional auscultation using an acoustic stethoscope while the cardiologists accessed recorded heart sounds of better fidelity from the same patients but without access to other clinical features. Furthermore, measures of the predictive accuracy of any diagnostic test are dependent on the prevalence of the disease, and significant VHD was present in only $14 \%$ of our study cohort.

\section{Implications for research and/or practice}

Our findings demonstrate that cardiac auscultation has only modest sensitivity for the detection of VHD in an asymptomatic population, and the low negative likelihood ratio suggests

\section{Key messages}

What is already known on this subject?

- Cardiac auscultation is widely taught, and it is believed to have some diagnostic accuracy for valvular heart disease (VHD) in symptomatic patients, but the ability to diagnose VHD in asymptomatic subjects is unclear.

What might this study add?

- Cardiac auscultation has limited accuracy for the detection of VHD in unselected asymptomatic patients and is a poor diagnostic screening tool in primary care, particularly for overweight subjects.

How might this impact on clinical practice?

- Echocardiography is likely to represent a better diagnostic strategy in patients with symptoms suggesting VHD or for VHD screening in general practice. 
that auscultation is a poor diagnostic tool for the screening of asymptomatic patients in primary care. Our data suggest that it may perform better in non-overweight patients (BMI $<25 \mathrm{~kg}$ / $\mathrm{m}^{2}$ ), and it is likely that diagnostic yield would be higher in those presenting with symptoms. The wider OxVALVE study indicates that the diagnostic yield of echocardiography is significantly increased by the inclusion of atrial fibrillation or cardiac symptoms as indicators of possible underlying $\mathrm{VHD}^{720}$-initial screening in this high-risk group could be performed using point-of-care echocardiography to reduce demand on scarce echocardiography resources. $^{21} 22$

Acknowledgements The authors thank Jacqueline Birks and Eleni Frangou from the Centre for Statistics in Medicine, Nuffield Department of Orthopaedics, Rheumatology and Musculoskeletal Sciences, University of Oxford for their help in statistical analysis of this study.

Contributors The study was conceived by BDP and SC. JH and AP performed the initial auscultation. AP acquired the subsequent electronic recording of the heart sounds. Analysis of the recorded heart sounds was performed by ML and Jd'A; and data analysis was performed by SKMG, AK, SGM and JW. The manuscript was drafted by SKMG and SGM and all authors have critically reviewed the manuscript.

Funding Supported by the National Institute for Health Research (NIHR) Biomedical Research Centre, Oxford.

Competing interests None declared.

Patient consent Not required.

Ethics approval The OxVALVE study has approval from the South CentralHampshire A Research Ethics Committee, REC reference: 09/H0502/58.

Provenance and peer review Not commissioned; externally peer reviewed.

(c) Article author(s) (or their employer(s) unless otherwise stated in the text of the article) 2018. All rights reserved. No commercial use is permitted unless otherwise expressly granted.

\section{REFERENCES}

1 Sztajzel JM, Picard-Kossovsky M, Lerch R, et al. Accuracy of cardiac auscultation in the era of Doppler-echocardiography: a comparison between cardiologists and internists. Int J Cardiol 2010;138:308-10.

2 Roldan CA, Shively BK, Crawford MH. Value of the cardiovascular physical examination for detecting valvular heart disease in asymptomatic subjects. Am J Cardiol 1996;77:1327-31.

3 Kinney EL. Causes of false-negative auscultation of regurgitant lesions: a Doppler echocardiographic study of 294 patients. J Gen Intern Med 1988;3:429-34.

4 Codispoti CA, Eckart RE, Rutberg SA, et al. Appreciation of precordial cardiac murmur on examination relative to knowledge of valvular heart disease. Cardiol Rev 2005:13:147-51.
5 Carapetis JR, Hardy M, Fakakovikaetau T, et al. Evaluation of a screening protocol using auscultation and portable echocardiography to detect asymptomatic rheumatic heart disease in Tongan schoolchildren. Nat Clin Pract Cardiovasc Med 2008;5:411-7.

6 Godown J, Lu JC, Beaton A, et al. Handheld echocardiography versus auscultation for detection of rheumatic heart disease. Pediatrics 2015;135:e939-e944.

7 d'Arcy JL, Coffey S, Loudon MA, et al. Large-scale community echocardiographic screening reveals a major burden of undiagnosed valvular heart disease in older people: the OxVALVE Population Cohort Study. Eur Heart J 2016;37:3515-22.

8 Baumgartner $\mathrm{H}$, Hung J, Bermejo J, et al. Echocardiographic assessment of valve stenosis: EAE/ASE recommendations for clinical practice. J Am Soc Echocardiogr 2009;22:1-23.

9 Lancellotti P, Tribouilloy C, Hagendorff A, et al. European Association of Echocardiography recommendations for the assessment of valvular regurgitation. Part 1: aortic and pulmonary regurgitation (native valve disease). European Journal of Echocardiography 2010;11:223-44.

10 Lancellotti P, Moura L, Pierard LA, et al. European Association of Echocardiography recommendations for the assessment of valvular regurgitation. Part 2: mitral and tricuspid regurgitation (native valve disease). European Journal of Echocardiography 2010;11:307-32.

11 Mangione S, Nieman LZ, Gracely E, et al. The teaching and practice of cardiac auscultation during internal medicine and cardiology training. A nationwide survey. Ann Intern Med 1993;119:47-54.

12 St Clair EW, Oddone EZ, Waugh RA, et al. Assessing housestaff diagnostic skills using a cardiology patient simulator. Ann Intern Med 1992;117:751-6.

13 Kumar K, Thompson WR. Evaluation of cardiac auscultation skills in pediatric residents. Clin Pediatr 2013;52:66-73.

14 Webb J, Theones M, Chambers JB. Identifying Heart Valve Disease In Primary Care: Differences Between Practice In Germany, France And The United Kingdom. Eur J Cardiovasc Med 2014;3.

15 Mangione S. Cardiac auscultatory skills of physicians-in-training: a comparison of three English-speaking countries. Am J Med 2001;110:210-6.

16 Jaffe WM, Roche AH, Coverdale HA, et al. Clinical evaluation versus Doppler echocardiography in the quantitative assessment of valvular heart disease. Circulation 1988;78:267-75

17 Lancellotti P, Rosenhek R, Pibarot P, et al. ESC Working Group on Valvular Heart Disease position paper-heart valve clinics: organization, structure, and experiences. Eur Heart J 2013:34:1597-606.

18 Nkomo VT, Gardin JM, Skelton TN, et al. Burden of valvular heart diseases: a population-based study. Lancet 2006;368:1005-11.

19 Lindekleiv $\mathrm{H}$, Løchen ML, Mathiesen EB, et al. Echocardiographic screening of the general population and long-term survival: a randomized clinical study. JAMA Intern Med 2013;173:1592-8

20 Chambers J, Kabir S, Cajeat E. Detection of heart disease by open access echocardiography: a retrospective analysis of general practice referrals. $\mathrm{Br} J$ Gen Pract 2014:64:e105-11.

21 Draper J, Chambers J. Detecting heart valve disease: can we do better? Br J Gen Pract 2016:66:156-7.

22 Arden C, Chambers JB, Sandoe J, et al. Can we improve the detection of heart valve disease? Heart 2014:100:271-3. 